Ana María Amar Sánchez y Claudia Hammerschmidt, Leonardo Padura y la poética de una nueva escritura política. Presentación ... ... ... .........

I. LA POLÍTICA EN TENSIÓN: ESTÉTICA Y ÉTICA

Lourdes DÁvila, Incitación del gesto. Teatro e historia en Máscaras, de

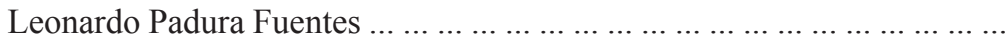

Carlos van Tongeren, La distribución de los cinismos en la narrativa de

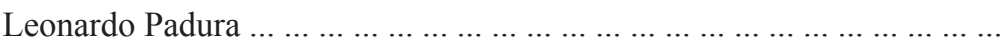

Ana María Amar SÁnchez, La imagen como pretexto. La narrativa de Padura

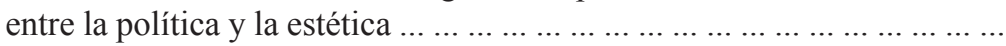

Claudia Hammerschmidt, Estéticas en lucha. La sublimidad de la pérdida en La novela de mi vida o el realismo estético de Leonardo Padura ... .... . María Pizarro Prada, "Pero escribí y el crimen fue menor". Mario Conde

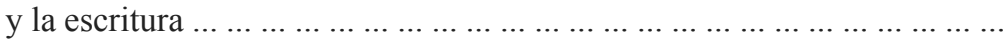

\title{
II. LA LITERATURA EN TENSIÓN: POLÍTICA E HISTORIA
}

Jonathan Dettman, Libertad condicional: subjetividad política e histórica

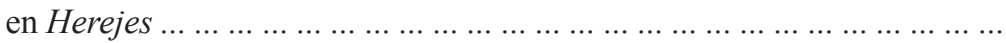

Rafael Rojas, Trotski y Cuba. Política, ficción e historia en la era pos-

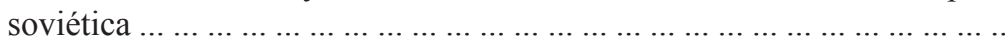

José Martínez Rubio, La Historia entre la libertad y la derrota. La generación posrevolucionaria en Herejes de Leonardo Padura 
JENNIFER Duprey, Travesía de una utopía rota: ekphrasis e historia en El hombre que amaba a los perros de Leonardo Padura

Ángel Esteban, Cuba, punto de (des)encuentro de la cultura occidental en la narrativa de Leonardo Padura

\section{NeCROLÓGICAS}

SARAH MojICA, Gloria Guardia de Alfaro (1940-2019) ... ... ... ... ... ... ... ...

\section{RESEÑAS}

FERnANDO Blanco sobre The Vanishing Frame: Latin American Culture and Theory in the Postdictatorial Era, de Eugenio Claudio Di Stefano ... .......

Fernando Degiovanni sobre The Senses of Democracy. Perception, Politics, and Culture in Latin America, de Francine R. Masiello ... ... ... ... ... ... ...

EMILY Hind sobre Strategic Occidentalism: On Mexican Fiction, the Neoliberal Book Market and the Question of World Literature, de Ignacio M. Sánchez Prado ... .

Aarti Madan Smith sobre Tierras en trance. Arte y naturaleza después del paisaje, de Jens Andermann ....................................

María del CARmen Marengo sobre Borges-Bioy en contexto: una lectura guiada de H. Bustos Domecq y B. Suárez Lynch, de Cristina Parodi ... ...

LuCIANO MARTínez sobre Los de abajo. Tres siglos de sirvientes en el arte y la literatura en América Latina, de María Julia Rossi y Lucía Campanella,

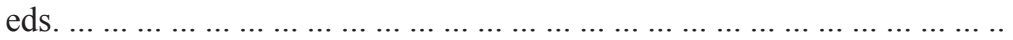

María del Pilar Ramírez GröBli sobre From the Tricontinental to the Global South: Race, Radicalism, and Transnational Solidarity, de Anne Garland Mahler

CONCEPCIÓN REVERTE BERNAL sobre Laboratorios de lo nuevo: revistas literarias y culturales de México, España y El Río de la Plata en la década de 1920, de Rose Corral, Anthony Stanton y James Valender, eds. ... ... ... YoAndy CABRERA sobre $t$ SURnamis vol. 1, de Eduardo Espina ... ............ José Gomariz sobre Casa en que nunca he sido extraña. Las poetas hispanoamericanas: identidades, feminismos, poéticas (Siglos XIX-XXI), de Milena Rodríguez Gutiérrez, ed. 
CARMela Zanelli sobre El imperio de la virtud. Grandeza mexicana (1604) de Bernardo de Balbuena y el discurso criollo novohispano, de Jorge L. Terukina Yamauchi .................................................

\section{Normas EDITORIALES}

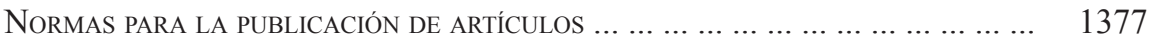

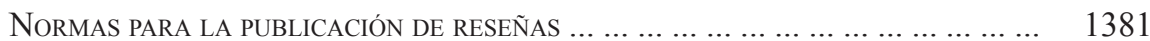

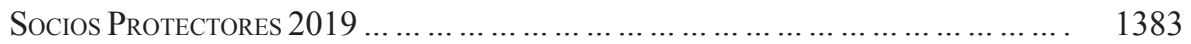

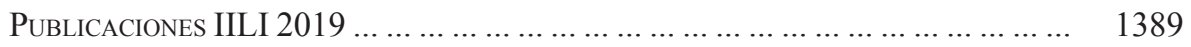


